\title{
PHILOSOPHICAL BASES OF MANAGEMENT OF SOCIOCULTURAL ACTIVITY
}

\section{Borinshtein Ye. R.}

\section{INTRODUCTION}

Problems associated with various aspects of the organization and regulation of human existence are priority for many areas of humanitarian knowledge. Man has always strived, and will strive to give his existence as much order as possible. It is inherent in human nature. Therefore, the study of managerial activity is constantly relevant.

Management, as a subject of research, has attracted philosophers since ancient times. But, only since the end of the XIX century, management problems stand out in a separate direction of scientific research. The subsequent XX century, with its inherent intensive development of production, became an even more favorable environment for concentrating the attention of researchers on various aspects of the conscious management of public life. By the middle of the second half of the 20th century, the world school of management consisted of dozens of diverse management trends that differed from each other both in the methods used and in their different views on the mechanism of social management.

Today, the study of managerial activity is becoming particularly acute. The need for its improvement is extremely relevant for modern Ukrainian society. History shows that ensuring the stability of society and its development is largely determined by the ability of people to maintain a social order and organize joint activities.

The 21 st century makes its demands on management. And here it is necessary to clearly understand that management activity is not constant, frozen in time. It develops and improves along with social evolution. At different points in time, in different cultural environments, managerial activity acquires specific features determined by a specific situation. It is always influenced by current values and worldviews.

Present time is a time when, according to many researchers, the current cultural landscape is changing. The existing sociocultural situation of human civilization is denied a new one, which has different characteristics and is built on different worldview paradigms. So, recently, with renewed vigor, questions have arisen about the place of man, as a subject of activity and knowledge, in the general picture of the world. Man in the modern picture of the world is perceived as an actively acting element of a holistic system of the 
universe. The content of management activity is changing due to the increasing role of man in the process of development of society. The issues of freedom, self-realization of the individual, the possibility of realizing his creative potential are being updated. The focus of the analysis of any human activity falls on its subjective characteristics. Therefore, consideration of managerial activity cannot be adequate without appeal to a person, to the specific facets of his personality, to his needs, motives, values and interests. Hence the increased importance of the management of sociocultural activity and the philosophical (systemic) foundations of its functioning.

\section{Systematic understanding of the sociocultural essence of management}

The modern world is characterized by constantly increasing flows of information, increased social dynamics. The main trends against which the managerial activities of today are realized are the flexibility of social relations, the irreducibility of a certain style of sociocultural dominant, and the fragmentation of human activity. These tendencies are especially pronounced in the modern sociocultural situation of postmodernity, which has occupied a dominant position in almost all areas of human activity. Today, postmodernism has become conceptualized as an expression of the "spirit of the times", as a special type of view of the surrounding reality.

It is important that the philosophical foundations in postmodern culture are based on irrational methods. Postmodernism, which arose as a result of criticism of rationality as a centralizing principle of cognition of the world, does not exclude alternative forms of perception of reality. On the contrary, human activity is akin to art, where rationality and logo-centrism play far from the main role. But abstract thinking, the development of mutual social adaptation in a constantly transforming society, is simply invaluable and allows people to advance along the constantly emerging new social elevators. In this context, the moment of consideration of the creative aspects of managerial activity, the possibilities and limitations of using intuition and imagination in management is updated.

A new vision of the world brings to the forefront such concepts as integrity, order, chaos, irreversibility, nonlinearity, fluctuation, uncertainty and the like.

The importance of research on the management of sociocultural activity is especially pronounced in the context of the transition of our society to a new form of relationship.

At the same time, determining the relevance of the chosen research topic, I am based on the existence of a number of insufficiently elaborated questions regarding the philosophical foundations of sociocultural activity management. Analyzing the existing scientific experience, there is the opportunity to 
develop a version of the socio-philosophical concept of management of sociocultural activity as a socio-cultural phenomenon, to try to rethink some of its features in the context of modern socio-cultural life of society.

Management research has a rich history. The analysis of the processes of conscious management of social life is devoted to the works of many thinkers of the past. The problems of the emergence and development of various management systems, their impact on society in an integral form are posed in the works of Plato, Aristotle, Lucretius Cara, Confucius, Menzi. From the standpoint of relations between the state and a person, management problems are considered by B. Spinoza, T. Hobbes, J. Locke, N. Machiavelli, S. Montesquieu, J.-J. Russo, K. Marx and others.

In the first works of theorists of scientific management F. Taylor, A. Fayol, G. Emerson, questions of the use of scientific methodology in the practice of managing the production and economic activities of organizations are raised.

The works of foreign scientists in this field of study are noted, first of all, by the study of individual subsystems of society. At the same time, emphasis is placed on the socialization of personality, group interactions, formal and informal structures (works by G. Simon, V. Thompson, J. March and other famous scientists).

Studies of management problems are often based on the application of interdisciplinary methods, including the scientific apparatus of natural disciplines. At the same time, the similarity of management processes in systems of various natures (technical, biological, social, cultural) is based on.

Along with representatives of cybernetics, the processes of managing society are studied by philosophers, sociologists, political scientists, and psychologists.

In general, an analysis of literary sources in the field of management issues gives reason to believe that socio-philosophical thought has an essential basis for further research on the problems of managing public life. Meanwhile, a number of fundamental issues need to be generalized and rethought. First of all, these are issues related to the determination of the nature and content of management activities, its principles and methods. The lack of sophistication of the socio-cultural conditioning of managerial activity is obvious. Some aspects of this problem were disclosed in the works of domestic authors. However, they do not allow reaching the proper conceptual height of socio-philosophical analysis, since they are largely mediated by a general ideological background, to the detriment of the objectivity of the study. The features of the manager's activity in modern sociocultural conditions are poorly covered. Existing publications in scientific journals are 
abstract in nature and are not able to provide holistic coverage of this problem.

Lack of experience and knowledge of the management of socio-cultural activities in a market economy, competition and the struggle for markets force us to learn, while mastering the basics and the pinnacles of mastery of science and management practice.

Doubts about sociocultural management were inspired by a number of objective and subjective factors. Socio-cultural activities, the structure of its organizations, institutions and bodies, the material base, personnel, forms and methods of work that have developed in domestic practice and have received a comprehensive scientific justification are unique in their own way. An undoubted blessing is the opportunity to study, compare, share the experience of socio-cultural activities with other countries.

Scientists and specialists convincingly reveal the presence of a number of dialectical factors in sociocultural activity - the need for conditions for both self-development and personality development, the presence of an informational, aesthetic, pedagogical space or environment, activities for organizing people's activities, sociocultural rehabilitation of vulnerable layers of society, the list goes on.

Putting forward such goals and solving the tasks corresponding to them, sociocultural institutions are transformed from subjects of socio-cultural activities to subjects of socio-cultural politics, entering into interaction, on the one hand, with cultural organs, and on the other, with public organizations, formations, foundations, the public and individuals. Such a chain of interconnections cannot develop without organization, without management on all floors of the vertical and horizontal relations.

Moreover, the sociocultural sphere, together with public, private institutions and the whole society, is immersed today in market relations, which seriously present completely new and stringent requirements for activity and management at all levels. This is especially important today, when Ukraine is in a pre-default state, weighed down by military operations.

In such conditions, the institutions of the socio-cultural sphere cannot work in the previous management model, they learn to manage rationally, introduce new forms of work, innovative types of activity. In other words, sociocultural activity has entered into new living conditions.

The skillful use of scientifically based management adapted to sociocultural activity means continuing vital development, remaining with hope only for the state - it is similar to death.

However, the turbulent and largely unpredictable economic and financial environment, sociocultural transformations, and legislative confusion sharply complicate the management process, making managerial decisions, increase 
the price of managerial errors and the importance of managerial skill, skillful management as a system and the personality of a manager.

In the modern era of postmodernization of social life and the development of personality and personal relations, the role of sociocultural as the basis of our existence is becoming increasingly important. By sociocultural, I mean the transcendental unity of the social and cultural, the essence of which is the need to consider society as a unity of culture and sociality, formed and transformed by human activity and the globalized sociocultural supersystems in which it is located.

A sociocultural understanding of reality begins to take shape in society around the end of the 18th century, but is scientifically formed thanks to the Russian-American scientist Pitirim Sorokin already in the 20th century and is expressed in his fundamental work "Social and Cultural Dynamics"1. Subsequently, some basic foundations of being sociocultural were created. We can distinguish the following, which seem to us paramount: the unity of the sociocultural (expressed by P. Sorokin); the manifestation of the social in the cultural and cultural in the social (expressed by $\mathrm{me}^{2}$ ); the ability of culture to act as a determinant of social interaction (according to T. Parsons); the connection of mental action with the "cultural... and social environment" ${ }^{3}$; any motives of human behavior can be fixed and described in culture (S. Akhiezer); the genotypic nature of man (according to V. Lartsev ${ }^{4}$ ). As you can see, socio-cultural has a very diverse understanding. However, this is just characteristic of the modern situation of postmodern society and postmodern culture.

The bottom line is that in modern society, sociocultural, based, it seems to me, on various kinds of values, under the onslaught of the philosophical system of postmodernity does not have a single foundation and represents a certain chaotic unity wandering in search of common value meanings. Thus, the sociocultural continuum is not presented in its sequence, which greatly complicates its analysis. This is manifested in almost any field of activity and in our actions. However, this fragmentation of consciousness cannot continue indefinitely, needing some universes, based on the human mentality.

The modern being of man and human, expressed in the creation of various management systems, provides us with the opportunity to create a modern system of socio-cultural unity, based on the management of socio-cultural

\footnotetext{
${ }^{1}$ Сорокин П. Социальная и культурная динамика. М.: Астрель. 2006. 1176 с.

${ }^{2}$ Борінштейн Є.Р. Особливості соціокультурної трансформації сучасного українського суспільства. Одеса: Асропринт. 2006. 400 с.

${ }^{3}$ Верч Дж. Голос раз ума. Социокультурный поход к опосредованному действию. М.: Тривол., 1996. $176 \mathrm{c.}$

${ }^{4}$ Ларцев В.С. Социокультурный генезис личности. К.: Принт-Экспресс. 2002. 360 с.
} 
activity as a method and science of managing people and socio-cultural supersystems based on the values of self-realization and mutual socio-cultural adaptation. Therefore, the management of sociocultural activities is of particular interest to modern society. With it, we can not only streamline the coordinate system of the socio-cultural sphere, but also develop human activity, its competence, the ability to create and develop technologies.

Moreover, the very specificity of the management of socio-cultural activities lies in its broad application to all areas of our lives. In addition, the understanding of the modern sociocultural sphere is very broad and includes activities both purely non-commercial (nonprofit) and commercial (paid services), both local and (including in relation to the same type of activity) of international scale. It seems important that management as a management system in its essence is engaged in ensuring the successful functioning of various sociocultural institutions aimed at the implementation of socially significant, useful for society activities. At the same time, in modern society, the management of sociocultural activity is characterized by the absence of a coherent system of mechanisms, mismatch of tasks, not clearly expressed goal setting, mismatch of functioning and management mechanisms. Hence we can talk about the need to create a management philosophy of sociocultural activity.

And in this philosophy, special importance should be given to the manager of sociocultural activities, who need to have a high level of professionalism, marketing, a high level of general culture and erudition, an understanding of the basic foundations of universal values. The multidimensional nature of the manager of the sociocultural sphere indicates the need to create a multidisciplinary highly qualified specialist, that is, a specialist who is stubbornly refusing the modern education system, including especially higher education. It is a specialist of this kind that could be used and organically exists in various types of activities related to: administration, multidisciplinary marketing and financing, the ability to provide and select staff, the organization of the entire creative process of any activity in the modern socio-cultural space.

Coordination of the activities of any team, which is required from a highly intellectual manager of socio-cultural activities, is determined by such factors as competence, a high level of creativity, an understanding of the essence of this particular organization, the ability to create a system of logical separation of labor and responsibility, the right choice of priorities and the ability to take into account hypothetically arising problems and solve overdue.

Therefore, we logically approach the need to create universes for the management of sociocultural activity as some unified complexes for managing the objective reality of the sociocultural sphere. The following universes seem important to us: the development of an analytical approach; the creation of a multilingual linguistic culture describing the sociocultural realities of life; the 
formation of an appraising and concrete attitude to the world; ability to manage multilayer socio-cultural groups; the creation of a socioculturally competent person, whose abilities and willingness to actively and transformatively participate in the dialogue of cultures in intercultural communication based on the principles of cooperation, mutual respect, tolerance and tolerance for sociocultural differences and overcoming sociocultural barriers are clearly expressed; high-quality universal system of higher education as the highest stage of development of a highly intellectual society.

The sociocultural system is largely associated with the great power of aesthetic and spiritual influence on all aspects of human life. The sociocultural system here not only "accompanies" or "frames" social and cultural reality, but is also actively included in it.

When it comes to trends and patterns in the development of a sociocultural system, one should simultaneously bear in mind both certain features of a person's lifestyle in this system and a certain direction of development of the system itself, its main elements and parts. Here, "social" and "cultural" not only closely interact, they are included in one another, and the functioning of the sociocultural system becomes a process.

The sociocultural system is a single complex of the existence of many social and cultural components, such as: finite elements (active and mass cultural and creative activities of people); interconnections of elements (sociocultural relations, interpersonal relations, cultural exchanges, interactions, communication, etc.); the functions of the elements of the system as a whole (the need for certain cultural and normative actions to preserve culture); borders (expanding opportunities for inclusion of people in cultural processes); subsystems (the number of amateur art collectives, amateur associations and interest clubs and other club groups); environment (creating conditions for cultural activities, interaction with neighboring sociocultural systems).

A holistic sociocultural system, like any other, is formed on the basis of its constituent elements, each of them, at the same time, can be an independent system if it is considered separately or as a subsystem in a holistic sociocultural system. Socio-cultural institutes are the backbone elements: state, non-state, private and public bodies, organizations and institutions that ensure the accumulation, storage and transmission of cultural property and cultural experience, the development of cultural, educational, creative forms of people's activities. This also includes numerous objects of institutions of a sociocultural sphere: houses of culture and clubs, libraries, theaters, museums, exhibition halls, parks of culture and recreation, circuses, entertainment venues, cinemas, sports and health resorts, health resorts, travel agencies and others. The system-forming elements include state and public committees, foundations and associations (protection of the child, motherhood and 
childhood, the disabled, veterans, social protection of the population, preservation of culture, support for young talents and so on).

The main task of sociocultural institutions is to combine the efforts of people to work together to meet the diverse needs of a person, to create conditions for satisfying his social, cultural, creative aspirations and life problems.

Thus, the sociocultural system is the most important component of the social life of society, purposefully performing the following functions: cultural preservation, cultural creation, enlightenment, training and education, social protection, research, design, communication, recreation, leisure and entertainment, information -advertising and others.

A sociocultural system can find equilibrium or instability, consensus or disagreement, harmony or contradiction, prosperity or crisis, depending on many factors. But, first of all, we note that the sociocultural system is constantly dependent on two factors: the natural need for cultural development and the level of people's consciousness.

Man, as you know, cannot exist outside his environment. He lives in a certain space and time, uses natural resources, affects the nature of the sociocultural environment, and, in this sense, his social and cultural life is as if immersed in it. The cultural environment is the primary and necessary environment social and cultural world of man. At the same time, people, being intelligent, thinking creatures, using symbols, signs, form beliefs, communication with each other, are immersed in the world of culture, both their own and their contemporaries, and even their predecessors, and it's impossible to imagine outside this process.

It is necessary to understand that any sociocultural system, its quality functioning, is directly dependent on qualitative sociocultural activity, which seems to us to be interpersonal (inter-individual) reality, in which there is a network of connections, attachments, dependencies, exchanges, and personal relationships. In other words, sociocultural activity is a kind of sociocultural tissue that connects people with each other. It can expand and contract, as individuals embed in or exit it. It strengthens or weakens the quality of interconnections, for example, from acquaintance and attachment to joint social and cultural activities.

Consequently, the sociocultural system is a kind of sociocultural space, with a highly saturated infrastructure of social, cultural objects and sociocultural relations, where knowledge, skills, values, norms, forms of communication, artistic-figurative models of reality are accumulated, preserved and developed. This is a place of realization of interests, expectations, needs of social groups and individuals. The functioning of the 
sociocultural system is directly dependent on the sociocultural process, the forms of its course, its essence and content.

The sociocultural process should be considered as a way of incorporating a person into the cultural life of society - in the system of its cultural relations, spiritual and moral values, domestic, family, industrial relations, and political device.

The ongoing changes in the socio-cultural system of society are polyative in nature and are reduced primarily to structural transformations. Meanwhile, undoubtedly, a radical reorientation of the principles and mechanisms of its development is necessary. Fundamentally new approaches to the activities of the sociocultural system can provide: development and implementation in practice of real economic mechanisms for the transition from a residual to a priority scheme of economic support for the development of culture; organization of a legal support system for the independent development of the cultural process, its pluralism with a guarantee of monopoly influence on the part of departments; transition from a prohibitive management model to a stimulating one; the transition from normative management methods to methods of regulating self-organizing cultural processes; transition to a regulated cultural market, protected from monopolization, both by legislative means and through economic stimulation of the diversity of cultural products.

We come to understand the following features of human society:

- sociocultural activity is carried out by us constantly;

- the quality of sociocultural activity depends on our ability to create and develop a sociocultural system;

- any sociocultural system is based on sociocultural processes in the individual, social group, society, society.

The existence of sociocultural activity is inextricably linked with the management of its activities, methods, methods. Sociocultural activity should someone manage and direct it in the right direction. Hence the importance of management as determining success-failure of all elements of the social system. Management efficiency is possible only with effective management and effective managers. First of all, let us indicate how management differs from management? Most experts and scientists agree that management is a kind of management, but differs from it in that it is more empirical, specific. Its essential focus is manifested in processes that ensure integration and the most efficient use of material and human resources in the interest of achieving goals. Management is one of the most important areas for ensuring the organization's vital functions, but it largely depends on qualifications, professionalism, socio-cultural, socio-psychological, socio-biological (first of all, health, and then the importance of appearance in all senses for the ability to please the client) qualities of managers. This causes reasonable high 
attention of scientists to the analysis of the place and role of managers in the process of ensuring the effectiveness of the organization and the role of management in the development of modern society.

\section{Philosofy of management of sociocultural activity}

The category "management" is of American origin and is usually interpreted as leadership, management. However, such an understanding of the category "management" does not fully reveal its meaning, since both leadership and management in economic systems have a specific meaning, which defines the categories of workers - "leader" and "manager".

In fact, the category "leader" usually refers to the first person who forms the goal, makes a decision and bears full responsibility for its implementation. A manager, or manager, is a manager who is obliged to fulfill the decision made by the leader and is responsible for his execution within the framework of his duties and the rights granted to him.

It seems to me that it is more appropriate to understand management as the art and science of managing human, intellectual, financial and material resources. In accordance with this interpretation, the manager will be defined as an official of the company, company, specialist in production management, circulation of goods, the work of the enterprise. The manager must rely on science and the art of leadership and management, combining them into a single management process. To do this, a qualitatively new specialist is needed - the manager, who is able to combine constantly replenished scientific knowledge and personal qualities in a single action, formed both by human nature and developed by practical experience, accumulated knowledge in the field of his professional activity.

The role of the manager in the organization's activities should be considered as a direct, personality-oriented sociocultural expression of the management process, its most important structural part. The manager's activity is aimed at ensuring that employees become not just an arithmetic sum of people with their problems and interests, but a close-knit team aimed at building up a social task, so that all the positive effects of a social organization for which people and unite in it so that the organization becomes an organization that benefits its members and society.

Management of sociocultural activity, from my point of view, is the highest art of managing other people or subordinates in the context of unifying with common grounds - achieving success, self-realization, and deriving pleasure from sociocultural activity that meets the individual's life priorities. Studying the theoretical and empirical foundations of sociocultural management, those forms, methods and management systems that are rapidly 
developing in Ukrainian reality, will not be effective if you do not understand the mechanisms of their formation.

Without detailing the historical facts and events of the existence of management as such, we note a number of fundamentally important points:

- in each specific type of activity, whether it is industrial production, trade, household services, social, social and cultural spheres, culture and others, management has its own specific, characteristic features and distinctive features;

- the nature and type of management are associated with the mentality of various people, with religious belief systems, traditions, customs and mores of society, types of industrial relations;

- a special sign of the professionalism of management of a particular structure is the category of creative activity that is directly related to the natural foundations of the socio-cultural sphere, where the primary qualities of management and manager are originality, flexibility, non-standard thinking, the ability to generate ideas, calculate adequate ways of their implementation and anticipate possible results.

Sociocultural activity refers, as you know, to the non-productive sphere, that is, it does not produce material products that form the country's national economic potential, but it produces a special type of product that has a consumer property.

It is easy to see that sociocultural activity, which is part of the nonproductive sphere, is only part of it, since such areas of activity as, for example, housing and communal services, public services, finances and credit, are difficult to correlate with sociocultural activity.

Intangible production in sociocultural activities, most likely, can be represented as "spiritual production" or the production of cultural, spiritual and social values and products.

But these values and products are not only intangible, some of them relate to material values and products, just as culture itself carries spiritual nonmaterial principles (knowledge, intelligence, morality, aesthetics, worldview, ways and forms of communication of people) and material (historical and cultural monuments, paintings, sculpture, masterpieces of writing, museum values).

The basis of material and spiritual cultures that are in organic unity is, of course, the development of material production. However, the material values of culture do not directly relate to the economic category of material products that form, as noted, the country's economy, but represent the highest value the cultural and national property of society. 
Spiritual and material cultural products have characteristic valueemotional qualities, thanks to which the cultural and spiritual needs of people are formed and satisfied.

In an open market, sociocultural activity becomes even more variable. Commercial, entrepreneurial activities, new types of private institutions of sociocultural service with night clubs, casinos, entertainment, information, cultural and leisure centers and other entertainment establishments are rapidly developing, which means that a variety of organizational, legal and economic opportunities for the development of sociocultural models open up activities.

It turns out that the management of sociocultural activity is directly dependent on the state; it is regulated by it and is formed by it with one degree or another of openness. Therefore, the management of sociocultural activity is the conscious activity of state institutions to regulate subject-object relations in all their diversity to achieve certain sociocultural goals.

Specific features of managing sociocultural processes are the concentration of management on the mechanisms for regulating sociocultural activities in accordance with the norms and principles, goals and objectives of cultural policy, including the regulation of financial, legal, organizational and administrative, personnel and other processes of functioning and development of sociocultural activities.

The philosophical foundations of public administration of the sociocultural sphere in modern Ukrainian society should be in the optimal approximation of traditional and innovative approaches to the development of culture, which focus on:

- new in keeping with tradition; using tradition as a prerequisite for modernization; secular organization of socio-cultural life, at the same time not excluding the significance of religion and mythology in the spiritual sphere;

- the value of each individual person, her values and interests;

- the liberal-democratic nature of power;

- combination of psychosocial, sociobiological and sociocultural characteristics of a person of a traditional and modern society;

- the effective use of science in the implementation of traditional value sociocultural orientations of a person.

The implementation of this will allow more accurately, on a scientific basis, to study the processes of acculturation, inculturation and multiculturalism, which, it seems to me, are actively developing in modern Ukrainian society. As a result, we observe active sociocultural changes, the interaction of traditional and modern culture as a result of various transformations, modernization and postmodernization of society.

At the same time, we will take into account the importance of a thoroughly developed optimal model for managing sociocultural activity, which is 
obliged to take into account the semantic content of the culture itself, the composition of its values, and development priorities.

Sociocultural activity is a self-developing system. The sociocultural system functions thanks to the activities of its constituent institutions, while the activity of the latter is due to human activity. The intensity of interaction between the system of institutions and man provides a particular level of sociocultural activity.

The diverse nature of the activities of managers and specialists in multilevel sociocultural organizations makes it possible to consider managers as specific specialists in the managerial sphere, taking into account their qualifications determined by the nature of substantive activity.

Considering the philosophical foundations of the management of sociocultural activity, we cannot ignore the understanding of the systemic meaning of all the management of sociocultural activity and its significance for man. We emphasize that the essence and meaning of any management efforts should imply a focus on improving a person's life. Hence, the goal of sociocultural management is to create conditions for implementing and combining the interests of all actors operating in the sociocultural sphere, namely: any sociocultural groups, self-organizing groups, creative groups, associations, organizations and institutions, social institutions, specialists for effective mutual action in the development of sociocultural processes, improving people's lives.

Therefore, it is in the outlined area that problems and solutions, difficulties and successes of our activity are concentrated; here we should look for optimal solutions for managing socio-cultural activities. It should be remembered: the main subject of management is a person acting as a customer, and creator, and performer of cultural policy and management.

And this means that the state, its institutions, determining their sociocultural policy, implementing holistic management of the sociocultural system, should contribute to the emergence of opportunities for the most efficient use of the potential of the entire sociocultural sphere, the identification of the creative potential of a person, and the realization of all his capabilities. As a result, the increasing role of the manager of sociocultural activities in modern society is increasing.

The manager of sociocultural activity as the aggregate subject of sociocultural processes plays a large role in the activities of professional and amateur culture-forming, creative and cultural-preserving organizations and institutions.

At the same time, he acts in different roles: as a regulator and organizer, in sociocultural self-organization, self-development and self-expression of a person in various forms of sociocultural creativity; as a carrier of cultural and 
value reference patterns, creator and translator of these patterns, cultural forms and values that comprise the content of sociocultural processes.

In this sense, a professionally prepared manager of sociocultural activity acts as an organizer of creative activity in culture and as a creator of its values.

Particular attention should be paid to the knowledge of the management of sociocultural activities and the creation of conditions for effective management. Such conditions can be direct-material, creative freedom, moral incentives and indirect- the free time budget, the development of communication tools, the level of education of those who create and those who consume. That is, it is about creating a certain culture of managing sociocultural activities. So, a modern understanding of the management of sociocultural activity should include categories in its sphere of interests: spirituality, sociocultural values, sociocultural norms, sociocultural ideals, sociocultural needs, and the like.

Such diversity gives a universal character to the philosophical foundations of the management of socio-cultural activities and the personality of the manager of the socio-cultural sphere. The value of the managerial profession is confirmed by the presence of a number of distinguished managers in various types of activities in the current Ukrainian government.

\section{CONCLUSIONS}

The processes that take place in the sociocultural sphere are diverse, complex and contradictory. They mirror and reflect the events and phenomena experienced by society and each individual person. In sociocultural activity, the main object of attention is a person, and his views, interests, intentions, actions, peace of mind and social order are formed and fixed in the process of this activity.

Sociocultural activity, like all other types of human activity, cannot develop successfully without professional and competent management, and without regulation that is positive for society.

One thing is certain - management has become an integral part of the various activities of socio-cultural institutions that provide the development of culture, art, science, education and other activities.

Denoting the objective and subjective difficulties of the formation and development of sociocultural management, let us outline a further perspective, which consists in studying the uniqueness of managerial relations in the field of culture, art, in the social space of a person.

Unfortunately, the problems of management methods and technologies precisely in sociocultural activity remain less developed and largely 
unadapted concepts and methods borrowed from foreign management technologies.

It seems to me central to the search for alternative solutions, the choice of which depends on the personality of the manager, his skills, abilities and skills to adapt to the constant transformations of all public institutions. Analysis and knowledge of the philosophical foundations of the management of sociocultural activity is the most correct way to the future.

Management of sociocultural activity can be considered as a given, as a fact, but the mechanisms for its implementation are in the process of formation and development.

Improving the effectiveness of management in sociocultural activity involves the use of the totality of modern achievements in this area. Therefore, to increase the productivity of managerial techniques, only experimental data are not enough. No less important is the wise use of the provisions of classical management, which is the basis of scientific management.

But in classical management, in general, you can find general, basic requirements for the effective management of industrial relations, the implementation of which in pure social activity is impossible. It follows that the development of management mechanisms should also be based on science that studies the specific features of sociocultural activity.

In other words, the development and implementation of mechanisms of sociocultural management can be successful when relying simultaneously on the general theory of management and the theory of sociocultural activity.

A comparison of the general managerial requirements with the sociocultural process reveals a circle of unresolved sociocultural problems, the resolution of which is important in itself and necessary for the effective management of the sociocultural sphere. It is the successful management of the sociocultural sphere that is the key to a successful society, self-realization of the individual.

\section{SUMMARY}

This work substantiates the importance of the philosophical foundations of the management of socio-cultural activities for the functioning of modern society. We consider the understanding of sociocultural as a transcendental unity of social and cultural, the essence of which is the need to consider society as a unity of culture and sociality, formed and transformed by human activity and the globalized sociocultural supersystems in which it is located. The role and significance of the sociocultural system for the development of management of sociocultural activity is investigated. It is indicated that sociocultural activity forms a network of ties, attachments, dependencies, 
exchanges and personal relationships. The categories of "management" and "manager" in the system of sociocultural activity are analyzed. The conditions of effective management of sociocultural activity are studied. The philosophical foundations of public administration of the sociocultural sphere in modern Ukrainian society are determined.

\section{REFERENCES}

1. Сорокин П. Социальная и культурная динамика. М.: Астрель. 2006. $1176 \mathrm{c}$.

2. Борінштейн Є.Р. Особливості соціокультурної трансформації сучасного українського суспільства. Одеса: Асропринт. 2006. 400 с.

3. Верч Дж. Голос раз ума. Социокультурный поход к опосредованному действию. М.: Тривол., 1996. 176 с.

4. Ларцев В.С. Социокультурный генезис личности. К.: ПринтЭкспресс. 2002. 360 с.

\section{Information about the author:}

Borinshtein Ye. R.,

Doctor of Philosophy, Professor, Head of the Department of Philosophy, Sociology, and Management of Sociocultural Activites, South Ukrainian National Pedagogical University named after K. D. Ushynsky 26, Staroportofrankivska str., Odesa, 65020, Ukraine 